\title{
Life history and reproductive behavior of the endemic Hawaiian Anomalochrysa hepatica (Neuroptera: Chrysopidae): A comparative approach
}

\author{
Maurice J. TAUBER ${ }^{1,2}$, CAtherine A. TAUBER ${ }^{1,2}$ and Timothy W. HILTON ${ }^{1}$ \\ ${ }^{1}$ Department of Entomology, Cornell University, Ithaca, NY 14853, USA; e-mail: mjt4@cornell.edu \\ ${ }^{2}$ Research Associate, Department of Entomology, Bernice P. Bishop Museum, Honolulu, Hawaii, USA
}

Key words. Neuroptera, Chrysopidae, Anomalochrysa hepatica, A. maclachlani, A. frater, Hawaiian endemic, green lacewing, temperature and development, egg predation, egg parasitoid, courtship, acoustic signals

\begin{abstract}
Our study focuses on a series of biological characteristics that Anomalochrysa hepatica exhibits; herein, we compare these features with those expressed by two other species within the endemic Hawaiian lacewing genus. Some of the characteristics (No. $2-3$, below) vary greatly among the three congeners and may be of phylogenetic importance; others (No. 1, below) probably are not. Our study showed the following: (1) Developmental response to temperature. Anomalochrysa hepatica's developmental rates under a range of temperatures parallel those of the congener A. maclachlani, but A. hepatica's thermal threshold is lower. It is possible that both species' developmental responses to temperature are subject to considerable geographic variation and thus are of little phylogenetic significance at the species level. (2) Larval color change. Third instars of $A$. hepatica undergo a striking color change as they mature. In expressing this trait, $A$. hepatica resembles its closely related congener, $A$. maclachlani, but differs from the more distantly related congener, $A$. frater. This color change may have phylogenetic importance. (3) Reproductive behavior. Courtship and mating in Anomalochrysa comprise a consistent sequence of behavioral elements, some of which differ among the three species. For example, during courtship, A. hepatica produces readily audible clicks that are associated with forward flicking of the forewings; in A. maclachlani, readily audible clicking occurs with simultaneous flicking of the fore- and hind wings; in A. frater wing-flicking is present but we did not perceive audible clicks. Some of the interspecific variation in mating behavior may also involve specific morphological modifications; aspects of both the behavioral and morphological variation may provide useful characters for phylogenetic study. (4) Oviposition and rates of egg survival in the field. Unlike other Chrysopidae, endemic Hawaiian Anomalochrysa, including A. hepatica, typically lay unstalked eggs; however, species vary in their patterns of egg laying. Both A. hepatica and A. maclachlani deposit clustered eggs, whereas $A$. frater lays eggs singly. In nature, the average rate of hatching per $A$. hepatica egg mass was $\sim 75 \%$. Several species of introduced predators and a species of trichogrammatid parasitoid attacked these eggs.
\end{abstract}

\section{INTRODUCTION}

The Hawaiian Islands, with their unique geological history, isolation and diverse climatic conditions, have been the site of rapid speciation and spectacular morphological and ecological diversification (Wagner \& Funk, 1995; Gillespie \& Roderick, 2002). Among the insect taxa that have undergone evolutionary radiations in Hawai' $i$ is the endemic lacewing genus Anomalochrysa. Presumably the group originated from the immigration of a single ancestor of undetermined identity; today, the $\sim 20$ Anomalochrysa species exhibit an intriguing array of morphological and biological traits that appear unique among chrysopid taxa (Zimmerman, 1957; Kuwayama, 1962; Hölzel, 1970; New, 1986; Brooks \& Barnard, 1990; Tauber et al., 1990, 1992).

Many of Anomalochrysa's traits could have considerable phylogenetic importance, both for identifying the group's ancestor and for examining the trajectory of its radiation on the Islands. Unfortunately, the comparative biology and functional morphology of the genus remain relatively poorly known; several reasons underlie this dearth of knowledge. For example, despite their once relatively common occurrence, populations of Anomalochrysa appear to have declined precipitously in the last century (Zimmerman, 1957), and their distributions are now largely confined to the remaining, relatively undis- turbed, montane forests. Many species are not readily encountered in the field.

This report is the third in a series aimed at proposing a phylogeny for Anomalochrysa based on comparative biological and morphological traits. Herein, we focus on Anomalochrysa hepatica McLachlan, a species that occurs on Oahu, Moloka'i, Maui, and Hawai'i. We present: (1) experimental data on the life history (development, oviposition and survival in relation to temperature), (2) detailed descriptions of the reproductive behavior (courtship, mating and oviposition, including a preliminary analysis of auditory signals associated with courtship), and (3) data on the natural enemies (predators and parasitoids). We compare $A$. hepatica's characteristics with those described for two other species (Tauber et al., 1990, 1992): Anomalochrysa maclachlani Blackburn a congener that Zimmerman (1957) included as a close relative of $A$. hepatica] and Anomalochrysa frater Perkins [a species that Zimmerman (1957) considered only distantly related to $A$. hepatica]. Also, we discuss how comparative data on the various biological traits might illuminate Anomalochrysa phylogeny.

\section{MATERIAL AND METHODS}

\section{Sites, stock and rearing}

Our stock of $A$. hepatica originated from fertile females collected at several localities in three districts on the Big Island of 
Hawai'i: North Hilo District - (1) Hilo Forest Reserve (above Laupahoehoe, 350-500 m); (2) Kipuka 'Ainahou, Pu'u O'o Trail (off Saddle Road, Upper Waiakea Forest Reserve, 1,675-1,900 m). Ka'u District - (3) Mauna Loa Strip Road, Volcanoes National Park (1,300-1,800 m); (4) Kipuka Puaulu, Volcanoes National Park (1,180-1,250 m); (5) Kapapala Ranch and Kapapala Forest Reserve (southwest of Pakoa Waterhole, 1,180-1,550 m). Hamakua District - (6) Mauna Kea State Park (near Pohakuloa $\sim 1,980-2,020 \mathrm{~m}$ ).

The collecting sites included moist, cool montane forest and dry, cool montane open woodland. At most localities, adults, larvae and egg masses were mainly associated with Acacia koa A. Gray (koa). Occasionally, specimens were taken on Metrosideros polymorpha Gaud. ('ohi'a lehua). In Mauna Kea State Park, we collected adults from Myoporum sandwicense Gray (naio, false sandalwood) and Sophora chrysophylla (Salisb.) Seem. (mamane). Acacia koa is either absent or uncommon at this site, and we did not collect larvae or egg masses there. However, at other sites in the Hamakua District, we found a few egg masses and larvae on mamane and another species of smooth-leaved shrub.

Unless otherwise indicated, our experimental animals were the first generation from field-collected females. Voucher specimens are deposited in the Cornell University Insect Collection (lot No. 1158), the Bishop Museum, Honolulu, and the U.S. National Museum, Washington, DC.

Larvae were reared on a diet of green peach aphids, Myzus persicae (Sulzer), and eggs of the angoumois grain moth, Sitotroga cerealella (Oliver). Adults received M. persicae on a leaf every one to two days; water and a mixture of protein hydrolyzate, Wheast ${ }^{\circledR}$, honey, and sugar (1:1:1:1 ratio, by volume) were continuously available. Except where stated, rearing was done at $21^{\circ} \mathrm{C}$. All experimental temperatures were maintained within $\pm 1^{\circ} \mathrm{C}$; humidity was not controlled.

\section{Influence of temperature: development, reproduction and survival}

Eggs from seven field-collected females (from adjacent sites on the Kapapala Ranch and Kapapala Forest Reserve) were distributed among five constant temperatures from 15.6 to $26.7^{\circ} \mathrm{C}$ at $16 \mathrm{~L}: 8 \mathrm{D}$ (Table 1). After the eggs hatched, we placed larvae in individual vials; each condition included 19-38 larvae. They had continuous access to $S$. cerealella eggs and $M$. persicae. Newly emerged females and males were paired and maintained under the temperatures at which they were reared. When an adult died, the surviving partner was given a new mate.

We recorded larval molts, cocoon spinning, pupal molts, adult emergence, dates of oviposition, fertility of eggs, and deaths. The prepupal stage was defined as the period from cocoon spinning to the larval-pupal molt within the cocoon; the preoviposition period was the time from female emergence to first oviposition. To analyze the relationship between temperature and development, we derived $K$ (heat degree-days, HDD) from the equation, $K=1 / y(x-t)$, where $y$ is the mean developmental rate, $x$ is temperature $\left({ }^{\circ} \mathrm{C}\right)$, and $t$ is the lower thermal threshold for development (see Tauber et al., 1990).

\section{Reproductive behavior}

We made our observations of reproductive behavior with the first-generation offspring of females that were collected in Kipuka Puaulu and Kipuka 'Ainahou, as well as on the Mauna Loa Strip Road; the sound recordings were made with stock originating only from Kipuka 'Ainahou. The adults were reared at 21 or $24^{\circ} \mathrm{C}(16 \mathrm{~L}: 8 \mathrm{D})$ and maintained in individual or same-sex cages for three to four weeks before pairing. We pho-

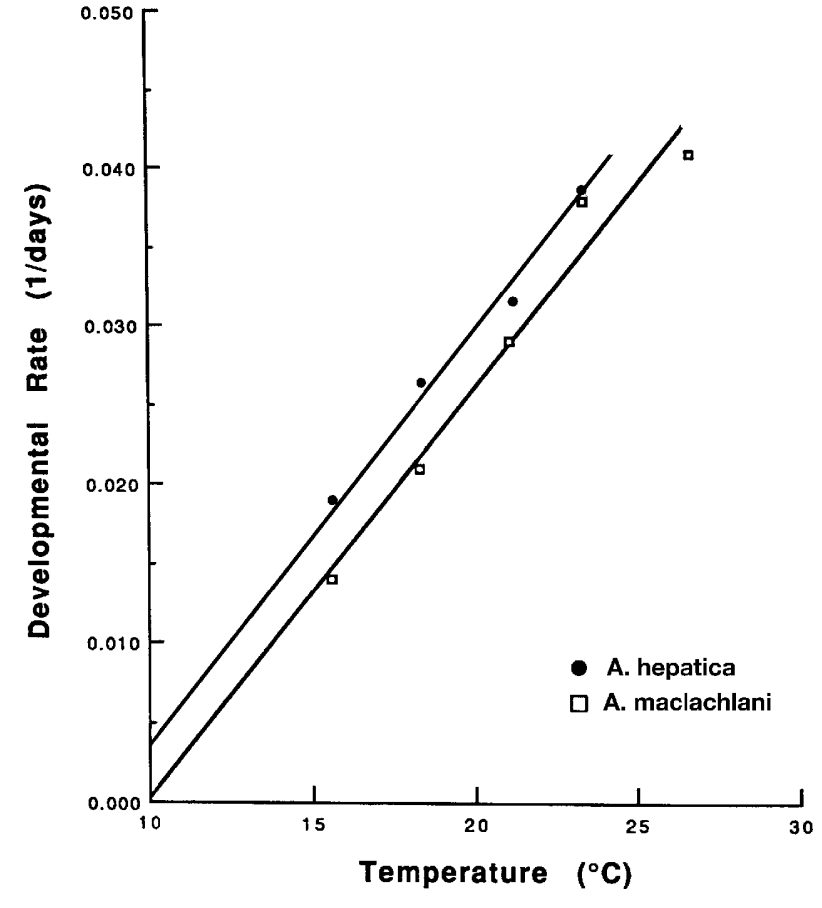

Fig. 1. Thermal influence on Anomalochrysa hepatica and $A$. maclachlani development (oviposition to adult emergence). $A$. hepatica - regression equation: $y=0.0025 x-0.0214, r=0.99 ; t$ $=8.7^{\circ} \mathrm{C} ; \mathrm{K}=406.9$ HDD. A. maclachlani - regression equation: $y=0.0026 x-0.0256, r=0.98 ; t=9.8^{\circ} \mathrm{C} ; \mathrm{K}=389.5 \mathrm{HDD}$ (Tauber et al., 1990).

tographed and recorded their behavior under laboratory conditions.

To record the clicking sounds associated with courtship, we used a Sony Walkman Pro Model WM-D6C cassette recorder, with a condenser microphone (Sony electret model 939LT). The microphone was hand-held above each performing lacewing; the lacewings (individuals, opposite-sex or same-sex pairs) were in 0.2751 cardboard cages covered with a fine-mesh cloth screen that allowed direct viewing from above. Thus the microphone was at variable distances from signaling animals, ranging from approximately five to seven $\mathrm{cm}$ (when the animals were on the floor of the cage) to within two cm (when they were on the cloth screening at the top). Recordings were done under room lighting at $21-23^{\circ} \mathrm{C}$. Spectral analyses were made from tape-recorded signals with "Canary", Cornell University Bioacoustics Workstation, Ver. 1.1.

\section{RESULTS AND DISCUSSION}

Our current study of $A$. hepatica identified several life history and behavioral characters that, when compared with those of $A$. maclachlani and $A$. frater, may help unravel the evolution of Hawai'i's unique endemic lacewings. Some of these characters vary at the generic level (i.e., they differentiate the endemic Hawaiian Anomalochrysa from other chrysopid genera); others vary at the species level. Below, we report and discuss our data and their potential value in comparative, phylogenetic studies.

\section{Influence of temperature on survival, development and reproduction}

Our analysis of $A$. hepatica's responses to temperature can be usefully compared with that obtained from $A$. 
TABLE 1. Survival and stage-specific thermal requirements for Anomalochrysa hepatica development (16L : 8D; first laboratorygeneration reared from females collected at Kapapala Ranch and Forest Reserve, Ka'u District, Hawai'i, HI).

\begin{tabular}{|c|c|c|c|c|c|c|c|}
\hline & \multicolumn{5}{|c|}{ Development, Mean \pm SD days } & \multicolumn{2}{|c|}{ Thermal requirements } \\
\hline & $15.6^{\circ} \mathrm{C}$ & $18.3^{\circ} \mathrm{C}$ & $21^{\circ} \mathrm{C}$ & $23.4^{\circ} \mathrm{C}$ & $26.7^{\circ} \mathrm{C}$ & $t\left({ }^{\circ} \mathrm{C}\right)$ & $K(\mathrm{HDD})$ \\
\hline Egg & $8.0 \pm 0$ & $6.0 \pm 0$ & $5.0 \pm 0$ & $3.4 \pm 0.5$ & $3.6 \pm 0.5$ & 10.9 & 46.9 \\
\hline First instar & $7.4 \pm 0.5$ & $5.0 \pm 0.3$ & $4.0 \pm 0$ & $2.7 \pm 0.6$ & $3.6 \pm 0.5$ & 8.6 & 50.4 \\
\hline Second instar & $6.7 \pm 0.5$ & $4.7 \pm 0.6$ & $4.0 \pm 0.6$ & $3.2 \pm 0.5$ & $3.3 \pm 0.5$ & 7.9 & 50.1 \\
\hline Third instar & $7.3 \pm 0.5$ & $6.1 \pm 1.0$ & $4.3 \pm 0.6$ & $3.9 \pm 0.3$ & - & 7.0 & 63.3 \\
\hline Prepupa & $10.0 \pm 0.5$ & $7.3 \pm 0.5$ & $5.4 \pm 0.5$ & $5.5 \pm 0.7$ & - & 9.3 & 64.1 \\
\hline Pupa & $18.9 \pm 0.7$ & $12.6 \pm 0.6$ & $10.4 \pm 0.5$ & $8.3 \pm 0.5$ & - & 8.8 & 124.8 \\
\hline Total & $58.5 \pm 0.8$ & $42.4 \pm 1.27$ & 33.1 & $26.5 \pm 0.7$ & - & 8.7 & 406.9 \\
\hline Number tested & 38 & 38 & 55 & 24 & 38 & & \\
\hline$\%$ survival to adult & 97.3 & 97.0 & 88.3 & 66.7 & 0 & & \\
\hline Sex ratio $(F: M)$ & $1.4: 1$ & $0.88: 1$ & $1.6: 1$ & $2.6: 1$ & - & & \\
\hline
\end{tabular}

All temperatures were $\pm 1{ }^{\circ} \mathrm{C} ; t$, lower thermal threshold for development; $K$ (HDD), number of heat-degree days above the lower thermal threshold that are required for completion of development.

maclachlani (Tauber et al., 1990) because both species were examined under similar conditions (range of temperatures, food, etc.). The regression lines that depict the influence of temperature on development were parallel for the two species, but their lower developmental thresholds and developmental rates under low and mid-range temperatures differed (Fig. 1).

In contrast to $A$. maclachlani, A. hepatica responded particularly well to low temperatures, but poorly to the higher ones we tested. For example, A. hepatica had 97\% survival under both 15.6 and $18.3^{\circ} \mathrm{C}$, versus $A$. maclachlani's $\sim 35 \%$ survival rate under the same two temperatures. Development by $A$. hepatica (from oviposition to adult emergence) was completed thirteen days faster under $15.6^{\circ} \mathrm{C}$ and four days faster under $18.3^{\circ} \mathrm{C}$, than was that by $A$. maclachlani (cf Table 1 here, with Tauber et al., 1990).

Both species had very similar developmental times at the mid-range temperature of $\sim 21^{\circ} \mathrm{C}$ (egg to adult emergence $=\sim 33$ days; Fig. 1). However, A. hepatica fared poorly at high temperatures. For example, all of the $A$. hepatica that we tested under the highest temperature $\left(26.7^{\circ} \mathrm{C}\right)$ died in early developmental stages (egg, L1, L2). This is unlike A. maclachlani's $56 \%$ survival rate under the same temperature.

In general, $A$. hepatica's fertility rate was lower than $A$. maclachlani's $\left(\sim 70 \%\right.$ versus $100 \%$ under $15.6-21^{\circ} \mathrm{C}$, and $42 \%$ versus $100 \%$ at $23.4^{\circ} \mathrm{C}$ ) (cf., Table 2 here with Tauber et al., 1990). With one notable exception $\left(15.6^{\circ} \mathrm{C}\right)$, temperature did not appear to have a large effect on A. hepatica's preoviposition periods, which generally ranged from 18 to 25 days. Notably, four out of eleven pairs at $15.6^{\circ} \mathrm{C}$ laid fertile eggs within a very short period (4 days). A preoviposition of four days is not unusual for chrysopids, but such a short duration generally occurs at considerably higher temperatures; we have no explanation for these short preoviposition periods.

The relatively good developmental and reproductive performance of $A$. hepatica under the low temperatures we tested was not unexpected, given the species' occurrence in cool montane situations. However, it was surprising that $A$. hepatica appears more highly adapted to cool conditions than the congeneric A. maclachlani, which shares many of the same habitats (Fig. 1). The usefulness of this type of comparative data (developmental responses to temperature) to phylogenetic studies of chrysopids has not been investigated; we suspect that, like many phenological traits, it is highly subject to local selection and geographic variation (see Tauber et al., 1986). As a consequence, homoplasy may be very common in these traits.

\section{Larval color}

A notable color change occurred during the maturation of $A$. hepatica third instars under all temperatures. Third instars, which are predominantly dull green, have a distinct pale yellow, mid-dorsal stripe along the thorax and abdomen. In young individuals, this stripe contains a small, very narrow and diffuse reddish stripe; as the third instars mature, the red stripe becomes darker, wider and more prominent (Fig. 2). Such a color change also occurs in A. maclachlani third instars, but not in those of $A$. frater.

The biological significance of this trait (color change in relation to larval maturation) is unknown, but we suggest

TABLE 2. Thermal influence on Anomalochrysa hepatica oviposition (16L : 8D; first laboratory generation reared from females collected at Kapapala Ranch and Kapapala Forest Reserve, Ka'u District, Hawai'i, HI).

\begin{tabular}{lcccc}
\hline & \multicolumn{4}{c}{ Temperature $\left( \pm 1^{\circ} \mathrm{C}\right)$} \\
\cline { 2 - 5 } & $15.6^{\circ} \mathrm{C}$ & $18.3^{\circ} \mathrm{C}$ & $21^{\circ} \mathrm{C}$ & $23.4^{\circ} \mathrm{C}$ \\
\hline Percent fertility (Number of pairs) & $73 \%(15)$ & $67 \%(15)$ & $72 \%(18)$ & $42 \%(7)$ \\
Preoviposition period & & & & $18.4 \pm 3.2$ \\
$\quad$ Mean \pm SD, days & $21.2 \pm 14.3$ & $25.4 \pm 5.9$ & $13-25$ & $22 \pm 7.2$ \\
Range, days & $4,23-37$ & $17-39$ & 12 & $16-30$ \\
Number of pairs & 11 & 10 & & 3 \\
\hline
\end{tabular}




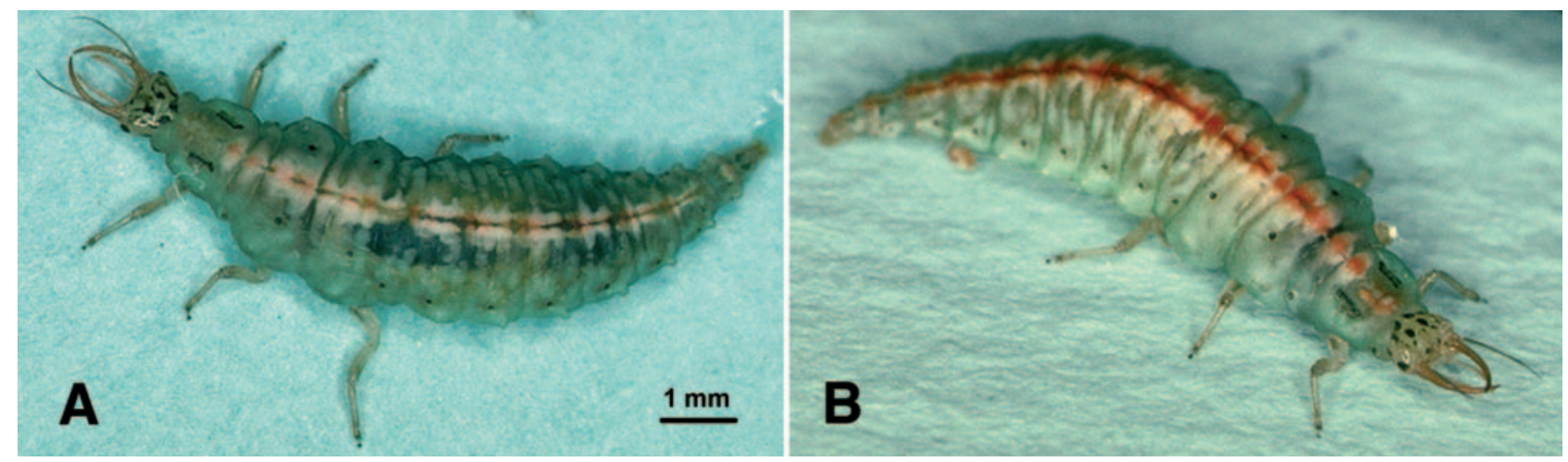

Fig. 2. Third instar Anomalochrysa hepatica. A - one-day old; B - mature. Note the red mid-dorsal stripe that develops as the larva matures.

that it should not be overlooked in phylogenetic comparisons.

\section{Courtship and mating behavior}

We observed the courtship of approximately twenty male-female pairs of $A$. hepatica; ten of these resulted in copulation. During these observations, the pairs exhibited a consistent sequence of courtship, mating, and postmating behavior, elements of which may be useful as traits in phylogenetic studies. They include the following: opening of the male genital chamber and everting the genitalia, wing-flicking and clicking (usually by both females and males), male-clasping of the female wings, male-grasping of the female abdomen, copulation, and post-mating feeding and grooming.

In the following three sections, we: (1) describe a typical sequence of courtship and mating behavior in $A$.
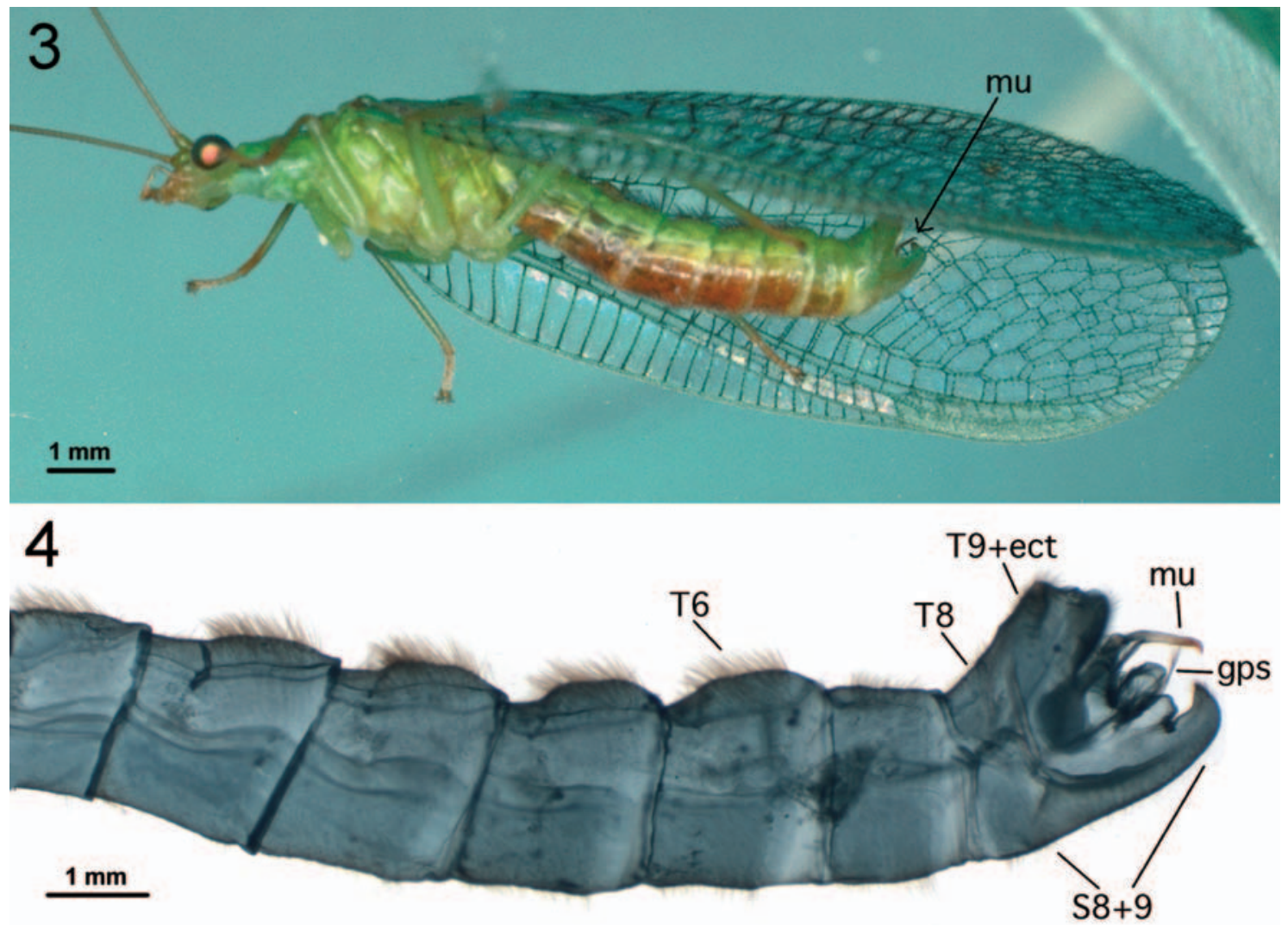

Fig. 3-4: Male Anomalochrysa hepatica. 3 - the genital chamber is opened and the elongate sclerotized mediuncus (arrow) extends outward (also see Fig. 4). 4 - abdomen (cleared in $\mathrm{KOH}$ and stained with clorozol black). S8 + 9 - fused sternites 8 and 9; T6 - sixth tergite, T8 - eighth tergite, T9 + ect - fused ninth tergite and ectoproct; gps - gonapsis; mu - mediuncus. Note that the tergites on segments 2 through 6 are heavily sclerotized and they bear long, dense, anteriorly slanting setae; these structures may help immobilize the female wings as the male attempts to copulate. Also, note that tergites 7 and 8 are particularly small and weakly sclerotized; presumably these features allow flexible movement of the abdominal tip. The genital chamber segments (8 and 9) are gaping; the heavily sclerotized mediuncus, which articulates basally on a sclerotized internal arch (gonarcus), is extended from its usual position (folded beneath the gonarcus and directed anteriorly). The gonapsis is flexible and extends posteriorly; its function is unknown. 

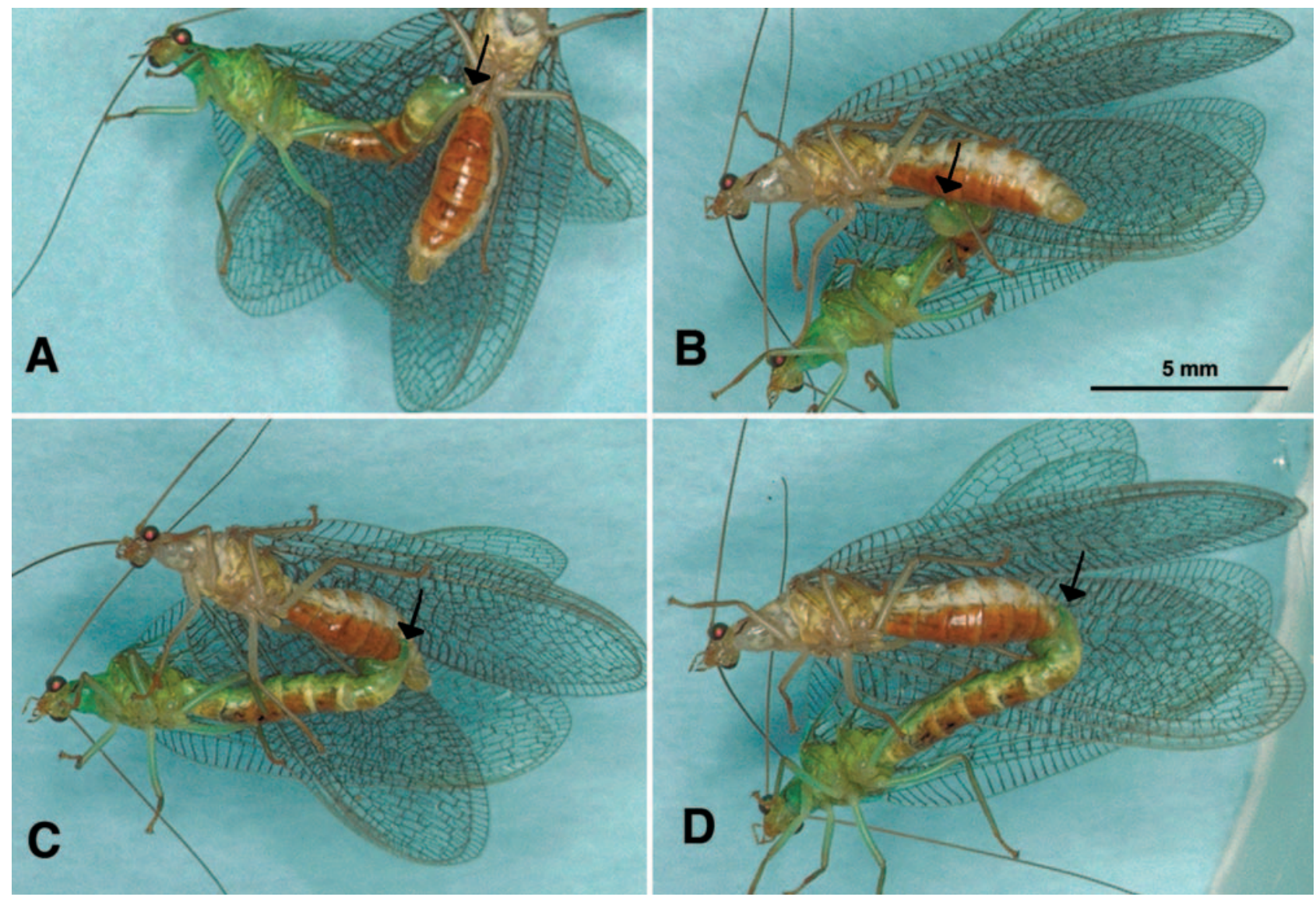

Fig. 5. Sequence of wing-clasping and abdomen-grasping by an Anomalochrysa hepatica male. The arrows indicate the position of the male's terminalia as they slide along the female's abdomen from base to tip. As his terminalia grasp her abdomen, the male's wings and abdomen hold her right pair of wings flat and immobile. Note that the male's setaceous abdominal tergites 3-6 remain in contact with her wings while he attempts to copulate.

hepatica, (2) characterize the sounds that are associated with $A$. hepatica's courtship, and (3) compare our observations with those reported for $A$. maclachlani and $A$. frater.

\section{Courtship}

When males of $A$. hepatica were at rest, the elongate ventral valve (sternite $8+9$ ) was held closed so that it covered the genitalia and much of the dorso-caudal plates (fused tergite $9+$ ectoproct) (e.g., Fig. 69 in Zimmerman, 1957). The first overt sign of courtship activity in $A$. hepatica was the opening of the male genital chamber so that the fused ninth tergite + ectoproct was perpendicular with the axis of the abdomen; the heavily sclerotized, hooked mediuncus was visible and extended outward from its usual position folded inward; and the gonapsis and dark base of the gonarcus were readily seen (Figs 3, 4). We did not observe glands being extruded while the genital chamber was open in A. hepatica; this differs from some other chrysopids (e.g., Meleoma, Chrysopa) in which extension of the abdomen during courtship is associated with extrusion of eversible glands (Tauber, 1969; Wattebled \& Canard, 1981).

Opening of the male genital chamber in A. hepatica was usually followed by either short or long bouts of alternating male and female wing-flicking and clicking.
Wing-flicking consisted of very rapid forward and back movement of the slightly elevated forewings (very rarely, both pairs of wings), and it was associated with distinctly audible clicks (see below). Either sex initiated wingflicking and clicking, but usually the female began after a male had opened his genital chamber. Females and males performed duets that consisted of two or more forewing flicks and clicks.

In a typical sequence of courting, after wing-flicking and clicking, the pair performed a series of rapid movements that included wing-clasping, abdomen-grasping and then coupling. First, the male and female moved closer toward each other and briefly assumed a position roughly facing each other. Then the male quickly swung the axis of his body approximately $180^{\circ}$ (leading slightly with the tip of his abdomen), thus orientating himself parallel to her. Concurrently, the female orientated her body toward the male with her abdominal tip inclined toward his. As their near-parallel bodies came close, the male positioned his wings above the female's two adjacent wings and swung his abdomen beneath her wings. His wings and abdomen then came together, clasping the female's forewing and hind wing, holding them flat, and immobilizing them. 


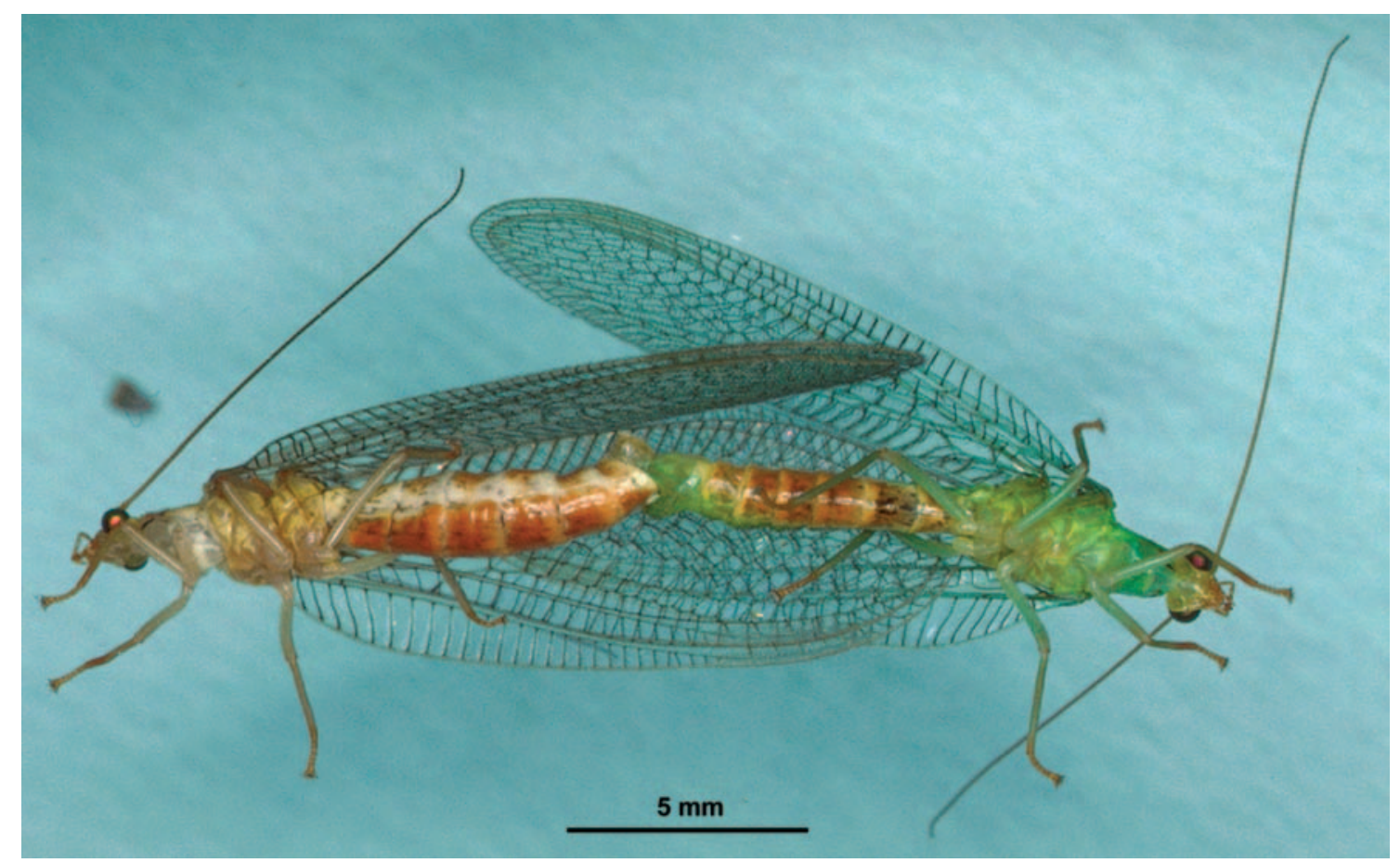

Fig. 6. Coupling by Anomalochrysa hepatica, “end-to-end" position, with an approximately $90^{\circ}$ twist in the male's abdomen. Note that the distal three to four segments of the female's abdomen are engulfed by his terminalia.

The male clasped the female's wings so that the costal margin of her forewing was wedged toward the base of his hind wings, and both her forewing and hind wing were held between his wings and his abdomen (Fig. 5A). The abdominal tergites of $A$. hepatica males are adorned with robust, anteriorly-directed setae (Fig. 4). These anteriorly inclined setae may help secure the female's wings and impede their sliding posteriorly out of the male's clasp.

The above sequence of precopulatory behavior was often interrupted and reinitiated. Interruptions occurred more frequently early in the sequence than later, and we could not determine whether the male or the female instigated them or why they occurred.

After the male had secured the female's forewing and hind wing (on one side) between both pairs of his flattened wings and his abdominal tergites, his widely opened, clasper-like terminalia grasped her near the base of her abdomen ( A1-A3) (Fig. 5A). His terminalia then simultaneously grasped and slid posteriorly along the length of her abdomen (Figs 5B, C, D). Coupling occurred when the tip of his abdomen reached hers.

\section{Copulation}

During the initial period of pairing, both partners' tarsi usually remained in contact with the substrate; their abdomens remained connected at approximately a $45^{\circ}$ angle; and the male's wings continued to hold the female's wings. His widely spread terminalia were attached to her terminalia from the side, and they engulfed the four to six distal segments of her abdomen (Fig. 6). Thus, his abdomen was twisted nearly $90^{\circ}$, and her abdomen, which remained relatively straight for the most part, was slightly twisted at its tip.
Pairs remained in the above position for up to $\sim 10 \mathrm{~min}$, at which time the male released the female wings and pairing continued, usually with the male and female facing in opposite directions, his wings raised, and her wings held sloped over her body (Fig. 6). His abdomen appeared to pulsate slowly during copulation, and hers showed a slight peristaltic-like movement. Pairs usually ended coupling by pulling apart linearly. The duration of pairing ranged from 16-31 min in ten matings (10 different pairs; mean $\pm \mathrm{SD}=21 \min 58 \mathrm{~s} \pm 4 \min 38 \mathrm{~s}$ ) and from $5-10 \mathrm{~min}$ in two sequential matings by an eleventh pair.

\section{Postmating behavior}

Both sexes of A. hepatica exhibited postcopulatory grooming and/or feeding that is typical of most chrysopids whose mating behavior has been described (e.g., Toschi, 1965; Tauber, 1969). The female curled her abdomen ventrally and forward between her legs and applied her mouthparts to her abdominal tip. In doing so, she appeared to groom and/or to feed on the white spermatophore that protruded from her genital chamber. Sometimes the male also curled his abdomen forward in a similar manner and applied his mouthparts to the tip of his abdomen.

\section{Homosexual behavior}

When in a cage containing a member (or members) of the same sex, both males and females exhibited frequent bouts of homosexual courtship. This included (a) female to female or male to male duets of wing-flicking and clicking, as well as (b) same-sex attempted copulation, in which partners assumed a typical "precopulatory stance" 
and swung their abdomens toward each other. During this behavior, males exhibited expansion of the terminalia.

Homosexual behavior, as occurs in A. hepatica, is not unusual among chrysopid species. It has been observed in Chrysoperla, Meleoma, and the congeneric $A$. maclachlani (Henry, 1979; Tauber et al., 1990; M.J. \& C.A. Tauber, unpubl. observ.).

\section{Clicking}

Clicking always preceded mating and ceased when contact was made; it also occurred during homosexual displays. Thus, it appears to be intimately involved in courtship. Nevertheless, in nature, clicking may have communicative functions other than in courtship.

The clicking sounds produced by $A$. hepatica were audible to us at a distance of approximately $2-3 \mathrm{~m}$, as duets or choruses of repeated clicks that were emitted by either sex; in all cases we observed, they were associated with wing-flicking.

Clicking was sometimes initiated by single individuals in cages, but usually it began when individuals were brought together or when individuals in nearby cages began clicking (usually a male and a female, but also same-sex pairs). Individuals clicked in an alternating fashion (duet), as if in response to each other. Establishment of clicking and maintenance of duets and choruses did not require visual or physical contact between individuals.

We did not establish how the clicks were produced, but invariably clicking was associated with very rapid, forward and back, flick-like movement of the forewings. As in $A$. maclachlani, we noted a sclerotized structure at the base of the $A$. hepatica forewings that may be involved in generating the sound.

Despite technical difficulties, we were able to make some analyzable recordings from seven males. We did not obtain clear recordings from females. The male recordings were made when only one individual in a cage was clicking. Although background noise was intrusive, the click trains were sufficiently clear to measure (e.g., Fig. 7). They contained from three to twenty-one clicks, with inter-click intervals (defined as the time from the peak of one click to the peak of the next) ranging from $0.47 \pm 0.06$ to $0.68 \pm 0.27 \mathrm{~s}$ (mean $\pm \mathrm{SD} ; \mathrm{N}=13$ and 6 clicks respectively). These values translate to $1.47-2.13$ clicks/second. Our spectral analysis of individual clicks was hampered by background noise, but it showed that clicks are composed of a broad band of frequencies from two to approximately seven $\mathrm{kHz}$, and that the relative power is less than that of $A$. maclachlani.

\section{Comparison of mating behavior: $A$. hepatica, $A$. maclachlani and $A$. frater}

The three Anomalochrysa species showed marked similarities, as well as differences in all phases of courtship and mating, except one - we do not know whether $A$. maclachlani or A. frater males open their genital chambers and evert their genitalia during early courtship, as does A. hepatica. Zimmerman (1957) reported that, like A. hepatica, A. maclachlani has an elongate ventral plate
Male 9326-1

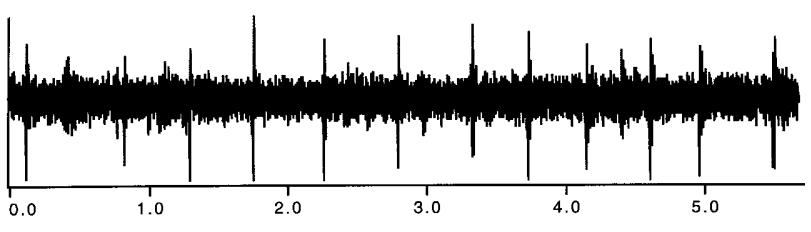

Male $9326-6$

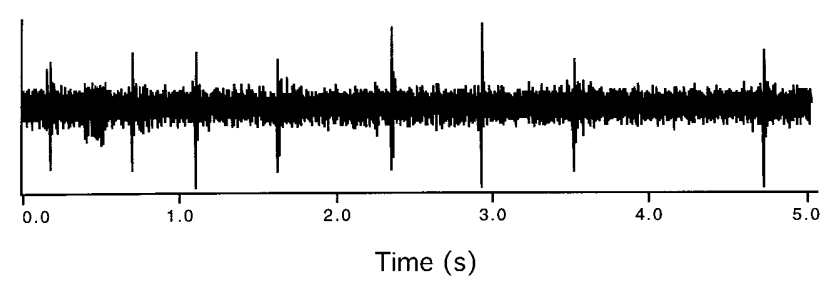

Fig. 7. Oscillographs depicting time display of clicks produced by two Anomalochrysa hepatica males during courtship. Vertical axis, click amplitudes in arbitrary voltage units; horizontal axis, time in seconds.

and holds its genital chamber closed when at rest. In contrast, A. frater is typical of a group of Anomalochrysa species that have short ventral valves and that hold their genital chambers open while at rest.

\section{Wing-flicking and clicking}

Wing-flicking behavior was present during the initial period of courtship in all three species. It persisted throughout mating in $A$. maclachlani, but ceased when male-female contact was made in A. hepatica (comparable data from $A$. frater are not available). Although clicking in A. hepatica and A. maclachlani is always associated with wing-flicking, the reverse is not always true. Wing-flicking by $A$. frater occurred without audible sounds.

Both $A$. hepatica and A. maclachlani resemble several other chrysopid species in that they produce sounds during courtship (references below). However, their sounds, and the mechanisms whereby they are generated, differ from those of other chrysopid taxa. First, the clicks that the two Anomalochrysa species make are readily audible to the human ear over a considerable distance (two or more meters). In contrast, the courtship signals of species in the genera Chrysoperla or Chrysopa are very weak and usually not audible to humans.

Second, the mechanism of sound production in the two Anomalochrysa species (loud clicks associated with anterior flicking of wings) has not been reported for other chrysopid genera. For example, in most Chrysopa and Chrysoperla species, acoustic signals result from vigorous abdominal vibrations, which are, at least in part, substrate-borne rather than airborne (e.g., Henry \& Wells, 2004). Species in other genera (Meleoma, Mallada) produce sounds with stridulatory organs, by "rustling" the wings, or by striking the wings against the substrate (Adams, 1962; Tauber, 1969; Duelli \& Johnson, 1981) all of which differ from those in $A$. hepatica and $A$. maclachlani. 


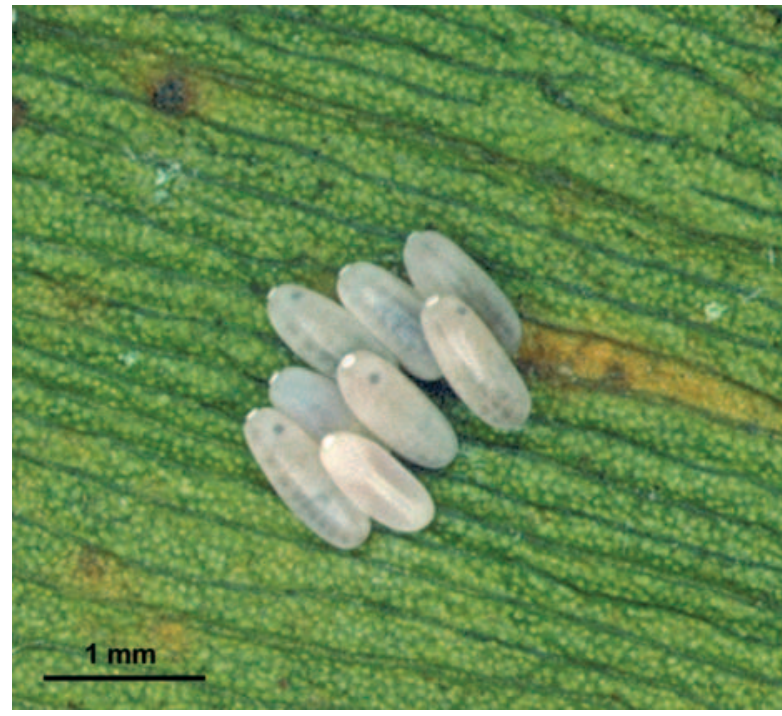

Fig. 8. An egg mass of Anomalochrysa hepatica on an Acacia koa leaf. (Note color and embryonic eye spots.)

Despite the noted similarities in the acoustic behavior of the two Anomalochrysa species, there are several marked differences. First, the clicking sounds in both species are associated with the anterior flicking of the wings, but in A. hepatica only the forewings are flicked; whereas in A. maclachlani, flicking involves both pairs of wings. Second, the sound that $A$. hepatica generates is not as loud to the human ear as that which $A$. maclachlani produces. Our spectral analysis (although not definitive) also indicated that the relative power of $A$. hepatica clicks was less than that of $A$. maclachlani's.

Third, A. hepatica produced fewer clicks during courtship than $\operatorname{did} A$. maclachlani. For example, some $A$. hepatica matings occurred after a very short bout of clicking - sometimes after only two or three clicks by either the male or female. Mating by $A$. maclachlani was associated with longer precopulatory duets. Also, clicking continued throughout courtship and copulation in $A$. maclachlani; in some cases, it persisted after the pair separated. In contrast, $A$. hepatica did not exhibit clicking during or after wing clasping; we never heard clicking (or observed wing-flicking) while the pair was coupled, even after the male and female wings had disengaged.

\section{Wing-clasping}

Like male $A$. hepatica, male $A$. frater clasp the female wings during courtship (M.J. Tauber \& C.A. Tauber, unpubl.); this element of courtship does not occur in $A$. maclachlani and is unreported from any other species of chrysopids. Both $A$. hepatica and $A$. frater also share a unique morphological adaptation that subserves the unusal wing-clasping behavior; i.e., males of both species (but not $A$. maclachlani) have long, anteriorly directed setae on abdominal tergites 1 through 6 (Fig. 4). These setae could help to secure the female's wings between his wings and abdomen during attempted copulation and the early part of mating. Among Anomalochrysa, this morphological modification is known only from $A$. hepatica and $A$. frater (Zimmerman, 1957); to our knowledge, it is unknown from other chrysopid taxa.

\section{Abdomen-grasping}

The manner in which the male A. hepatica terminalia grasp the female abdomen near its base and slide down her abdomen toward her genital opening is unusual. We did not observe it during either $A$. maclachlani's or $A$. frater's mating behavior, and it has not been reported from any other chrysopid species whose mating behavior has been examined. Superficially, it resembles the behavior of Nothochrysa californica Banks in which the tip of the male abdomen taps the female's abdomen at approximately the sixth segment and slides down the remainder of her abdomen, but the terminalia were not reported to grasp the female abdomen as in A. hepatica (Toschi, 1965).

It is noteworthy that $A$. hepatica's heavily sclerotized and widely separated (clasper-like) terminalia (specifically sternite $8+9$, tergite $9+$ ectoproct, and mediuncus) appear well structured for holding the female abdomen (Fig. 4). Similarly modified structures occur on the males of other Anomalochrysa species, but their involvement in mating is not known.

Finally, the male's engulfment of the female terminalia and his right-angled attachment to her during the initial period of pairing appear unusual and are unreported for other chrysopids. Principi (1949), in her exceptionally detailed and beautifully illustrated morphological study of the Chrysopa genital apparatus, shows the typical chrysopid copulatory stance. That is, the male tergites are on a plane with the female sternites, and the copulatory
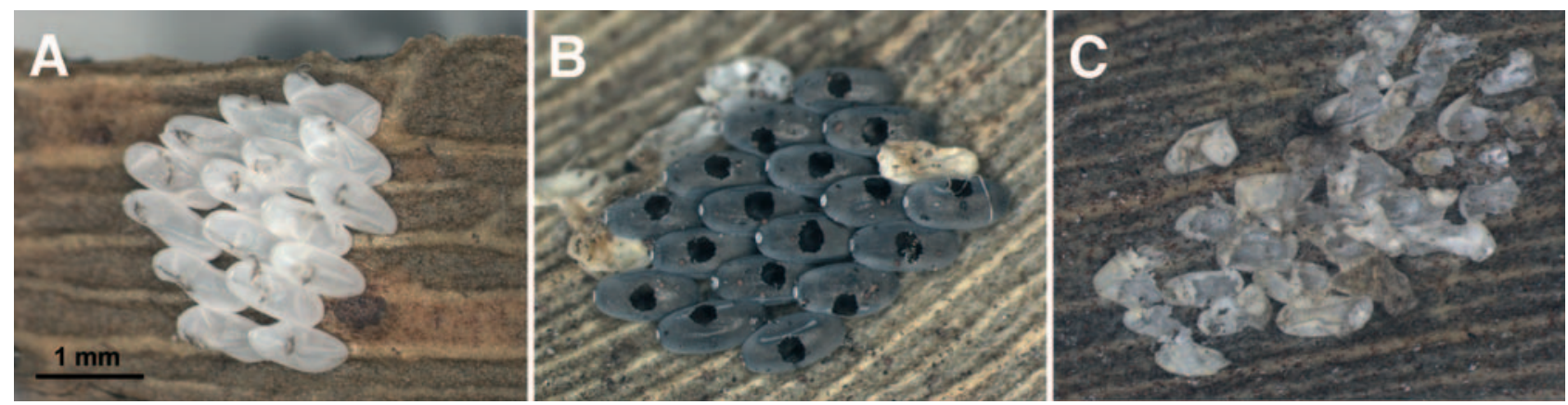

Fig. 9. Egg masses of Anomalochrysa hepatica that have (A) hatched, (B) been attacked by the parasitoid Trichogramma sp., (C) been attacked by the coccinellid Chilocorus nigritus. 
position is "male above", "female above", or "end-to-end" with the male inverted or the male abdomen twisted $180^{\circ}$ (Richards, 1927). Several of the above positions have been reported for chrysopids: "female above" [Nothochrysa, Meleoma, Chrysoperla (Toschi, 1965; Eichele, 1972; Henry, 1979)]; "end-to-end" with male abdomen twisted [Chrysopa (Toschi, 1965; Wattebled \& Canard, 1981)] or "male inverted" (Tauber \& Tauber, unpubl. observ.).

In Anomalochrysa, both A. maclachlani and A. frater have the typical alignment of the female's dorsum with the male venter and the male abdomen twisted $180^{\circ}$ (Tauber et al., 1992; Tauber \& Tauber, unpubl. observ.). Thus, A. hepatica's copulatory stance, with the male dorsum and venter aligned with the female's pleural regions (Figs 5D, 6), is unique among the chrysopids that have been studied. It is possible that the female's abdomen twists terminally so that the male and female abdomens have the typical alignment, but the female's terminalia are engulfed by his large genital chamber and thus are not visible (Fig. 6).

\section{Stimuli involved in A. hepatica mating behavior}

Our results lead us to speculate that chemical, auditory, visual, tactile, or a combination of stimuli could function in A. hepatica mating behavior. First, the opening of the male genital chamber, which always preceded mating is suggestive of the emission of chemical cues. Wingflicking, which is associated with sound production in $A$. hepatica, could also provide visual stimuli or help direct chemical signals. Finally, the male terminalia come into contact with the entire length of the female abdomen prior to coupling; it is possible that this behavior, aside from grasping the female, includes an exchange of tactile and/or chemical cues between the male and female. Detailed comparative analyses of such stimuli and the responses to them could be of considerable phylogenetic value.

\section{Oviposition}

The endemic Hawaiian Anomalochrysa lineage exhibits a unique form of oviposition; unlike the stalked eggs that typify all other chrysopid taxa that have been studied, Anomalochrysa's eggs are sessile. Moreover, significant aspects of Anomalochrysa's oviposition behavior vary (Tauber et al., 1990, 1992), and we expect that documentation of this variation will have phylogenetic value.

Females of $A$. hepatica deposit batches of eggs that resemble those of $A$. maclachlani in that the unstalked eggs are arranged side-by-side in a slightly slanted pattern, with the sides of the eggs attached to the substrate (Fig. 8). This pattern differs from A. frater's habit of laying single sessile eggs.

In comparison with $A$. maclachlani, $A$. hepatica lays significantly fewer eggs per batch, but egg size does not differ significantly between the two species (Table 3). The eggs of $A$. hepatica are bluish gray to olive green at oviposition and become darker gray as they mature; the pigmented larva is visible beneath the chorion. In
TABLE 3. Anomalochrysa hepatica eggs compared with those of A. maclachlani.

\begin{tabular}{lcc}
\hline & A. hepatica & A. maclachlani \\
\hline Number of eggs per batch & & \\
Range & $6-27$ & $16-50$ \\
Mean \pm SD & $15.5 \pm 6.0$ & $28.1 \pm 11.0$ \\
Number of batches & 55 & 14 \\
\hline Interspecific comparison & $\mathrm{t}=3.447 ; \mathrm{P}=0.004$ \\
\hline Length, mm & \multicolumn{3}{c}{} \\
Range & $1.00-1.09$ & $1.01-1.12$ \\
Mean \pm SD & $1.07 \pm 0.05$ & $1.06 \pm 0.03$ \\
Number of eggs & 10 & 20 \\
\hline Interspecific comparison & $\mathrm{t}=1.056 ; \mathrm{P}=0.350$ \\
\hline Width, mm & & \\
Range & $0.49-0.52$ & $0.43-0.54$ \\
Mean \pm SD & $0.50 \pm 0.01$ & $0.49 \pm 0.03$ \\
Number of eggs & 10 & 20 \\
\hline Interspecific comparison & $\mathrm{t}=1.580 ; \mathrm{P}=0.190$ \\
\hline
\end{tabular}

contrast, A. maclachlani eggs are white when laid, turning grey before hatching.

We observed an $A$. hepatica female during oviposition. Initially, she tapped the substrate with the tip of her abdomen. Peristaltic contractions of her abdomen were visible as she curved her abdominal tip downward to the substrate, paused, and extruded an egg. As she deposited the egg, she extended her abdominal tip away from her body. This motion was repeated until the cluster of eight eggs was laid. We do not have equivalent data from either $A$. maclachlani or A. frater for comparison.

\section{Natural enemies of $\boldsymbol{A}$. hepatica eggs}

During our study, we collected a total of fifty-five $A$. hepatica egg masses on Acacia koa in Kipuka Ainahou. Nearly all of the clusters had hatched before we collected them; many showed signs of predation and parasitism. Some of the predators [e.g., the most common predator in the area, the introduced coccinellid Chilocorus nigritus (F.) (det. J.K. Liebherr) left recognizable traces of the egg mass attached to the leaf surface; hatched and parasitized eggs were also readily identified (Fig. 9). Thus we were able to estimate rates of hatching, egg predation, and egg parasitism at this locality.

Among the field-collected egg masses, the average rate of hatching per egg mass was $73.3 \pm 34.6 \%$ (mean $\pm \mathrm{SD}$, $\mathrm{N}=54$ egg masses; range $=0-100 \%$ ). Three egg masses (5.6\%) were parasitized by Trichogramma sp. (det. J.D. Pinto). Most of the eggs in each of the three clusters were parasitized ( $n=19 / 19,10 / 15,17 / 23)$; the eggs in the two batches that were not parasitized did not hatch; they were collapsed. It is unknown whether this parasitoid (which J.D. Pinto believes is undescribed) is endemic or introduced; however, endemic trichogrammatids are known from the Hawaiian Islands (Howarth \& Mull, 1992).

Predation appeared to be the major cause of egg mortality; $31.5 \%$ of the egg masses that we collected showed some predation by chewing or piercing predators. Usually only a few eggs were fed upon, but in one case, all of the eggs $(n=25)$ in the cluster were attacked. Both in the 
field and in the laboratory, we observed adults and larvae of the coccinellid $C$. nigritus, as well as $A$. hepatica larvae, preying on $A$. hepatica eggs and neonate larvae. Other common predators at the site included another immigrant species of coccinellid, Leis conformis (Boisduval) (det. E.R. Hoebecke), a nabid species, a syrphid species, and the Nearctic brown lacewing, Hemerobius pacificus Banks.

Because $A$. hepatica is the only Anomalochrysa species for which we have field data regarding natural enemies, interspecific comparisons are not possible. However, most of the above predators that we found associated with $A$. hepatica eggs in Kipuka 'Ainahou are probably general predators, and they may attack other Anomalochrysa species, as well. Most were introduced to the Hawaiian Islands in recent decades (see Howarth \& Mull, 1992). What effect these predators have on A. hepatica and other endemic lacewing populations is unknown. But, their impact could be significant for several reasons: First, the potential for general predators to reduce endemic insect populations is well known (Lynch \& Thomas, 2000; Symondson et al., 2002; Ehler, 2004). Second, A. maclachlani eggs were shown to be susceptible to attack by Telenomus lobatus Johnson \& Bin, a continental parasitoid that attacks neuropteran eggs (Ruberson et al., 1989). And third, populations of Anomalochrysa are reported to have decreased drastically since the mid to late $1800 \mathrm{~s}$ when T. Blackburn and R.C.L. Perkins made their lacewings collections (Zimmerman, 1957). For these reasons, it would be instructive to evaluate the influence of introduced (as well as native) predators and parasitoids on $A$. hepatica and other species in the endemic Hawaiian genus Anomalochrysa.

ACKNOWLEDGEMENTS. We greatly appreciate the generosity and hospitality of K.Y. Kaneshiro (University of Hawai'i) during our studies in Hawai'i. Also, it is a pleasure to acknowledge the cooperation and help of the following individuals during various phases of the study: W.D. Duckworth, N.L. Evenhuis, B. Gagne, J.G. Giffon, R.G. Gillespie, B. Gollands, E.R. Hoebecke, F.G. Howarth, R.R. Hoy, T. de León, J.K. Liebherr, J.I. López Arroyo, S.E. Miller, J.R. Nechols, J.D. Pinto, J.R. Ruberson, C.P. Stone, W. Stormont, A.J. Tauber, M.J. Tauber, P.J. Tauber, S.B. Tauber, E. Vogt, and S.W. Woo. We also thank L.E. Ehler, D. Ullman, and the Department of Entomology, Davis, for their cooperation. The work was supported in part by the National Science Foundation (BSR8817822), the National Geographic Society, NRI-USDA Competitive Grants 9802447 and 2002-35316-1231, Regional Project W-1185, and Cornell University.

\section{REFERENCES}

Adams P.A. 1962: A stridulatory structure in Chrysopidae. PanPac. Entomol. 38: 178-180.

Brooks S.J. \& BARnARD P.C. 1990: The green lacewings of the world: a generic review (Neuroptera: Chrysopidae). Bull. Br. Mus. Nat. Hist. (Entomol.) 59: 117-286.

Duelli P. \& Johnson J.B. 1981: Behavioral origin of tremulation, and possible stridulation, in green lacewings (Neuroptera: Chrysopidae). Psyche 88: 375-381.

EHLER L.E. 2004: An evaluation of some natural enemies of Spodoptera exigua on sugarbeet in northern California. BioControl 49: 121-135.
EICHELE G. 1972: Über das Sexualverhalten der Florfliege (Chrysopa carnea St.). Schweizer Jugend Forscht 5: 3-7.

GILlesPIE R.G. \& RoDerick G.K. 2002: Arthropods on islands: colonization, speciation, and conservation. Annu. Rev. Entomol. 47: 595-632.

HENRY C.S. 1979: Acoustical communication during courtship and mating in the green lacewing Chrysopa carnea (Neuroptera: Chrysopidae). Ann. Entomol. Soc. Am. 72: 68-79.

Henry C.S. \& Martínez Wells M.L. 2004: Adaptation or random change? The evolutionary response of songs to substrate properties in lacewings (Neuroptera: Chrysopidae: Chrysoperla). Anim. Behav. 68: 879-895.

HöLzEL H. 1970: Zur generischen Klassifikation der paläarktischen Chrysopinae. Eine neue Gattung und zwei neue Untergattungen der Chrysopidae (Planipennia). Z. Arbeitsgem. Österr. Entomol. 22: 44-52.

Howarth F.G. \& Mull W.P. 1992: Hawaiian Insects and their Kin. University of Hawaii Press, Honolulu, 160 pp.

LyNCh L.D. \& Thomas M.B. 2000: Nontarget effects in the biocontrol of insects with insects, nematodes and microbial agents: the evidence. Biocontr. News Inform. 21: 117-129.

Kuwayama S. 1962: A revisional synopsis of the Neuroptera in Japan. Pac. Insects 4: 325-412.

NEw T.R. 1986: Notes on the larva of Anomalochrysa McLachlan (Neuroptera, Chrysopidae). Neuroptera Int. 4: 31-34.

PrinciPI M.M. 1949: Contributi allo studio del Neurotteri italiani. VIII. Morfologia, anatomia e funzionamento degli apparati genitali nel gen. Chrysopa Leach (Chrysopa septempunctata Wesm. e C. formosa Brauer). Boll. Inst. Entomol. Univ. Bologna 17: 316-362.

RichaRdS O.W. 1927: Sexual selection and allied problems in the insects. Biol. Rev. 3: 298-364.

Ruberson J.R., Tauber C.A. \& Tauber M.J. 1989: Development and survival of Telenomus lobatus (Hymenoptera: Scelionidae), a parasitoid of chrysopid eggs: effect of host species. Entomol. Exp. Appl. 51: 101-106.

Symondson W.O.C., Sunderland K.D. \& Greenstone M.H. 2002: Can generalist predators be effective biocontrol agents? Annu. Rev. Entomol. 47: 561-594.

TAUBER C.A. 1969: Taxonomy and biology of the lacewing genus Meleoma (Neuroptera: Chrysopidae). Univ. Calif. Publ. Entomol. 58: 1-94.

TAuber C.A., Johnson J.B. \& TAuber M.J. 1992: Larval and developmental characteristics of the endemic Hawaiian lacewing, Anomalochrysa frater (Neuroptera: Chrysopidae). Ann. Entomol. Soc. Am. 85: 200-206.

Tauber M.J., Tauber C.A. \& Masaki S. 1986: Seasonal Adaptations of Insects. Oxford University Press, New York, 411 pp.

Tauber M.J., Tauber C.A., Hoy R.R. \& Tauber P.J. 1990: Life history, mating behavior, and courtship songs of the endemic Hawaiian Anomalochrysa maclachlani (Neuroptera: Chrysopidae). Can. J. Zool. 68: 1020-1026.

Toschi C.A. 1965: The taxonomy, life histories, and mating behavior of the green lacewings of Strawberry Canyon (Neuroptera: Chrysopidae). Hilgardia 36: 391-431.

WAGNER W.L. \& FunK V.A. (eds) 1995: Hawaiian Biogeography. Smithsonian Institution Press, Washington, DC, 467 pp.

Wattebled S. \& CANard M. 1981: La parade nuptiale et l'accouplement chez Chrysopa perla (L.) (Insecta, Neuroptera, Chrysopidae. Rôle des vésicules exsertiles du male et variation de la parade en fonction de la réceptivité de la femelle. Ann. Sci. Nat. (Zool.) 3: 129-140.

Zimmerman E.C. 1957: Ephemeroptera, Neuroptera, Trichoptera. In: Insects of Hawaii. Vol. 6. University of Hawaii Press, Honolulu, 209 pp.

Received September 21, 2005; revised and accepted January 17, 2006 